\title{
Positivismo en México. Un estudio sobre la obra México: su evolución social
}

\section{Positivism in Mexico. A Study of the work Mexico, its Social Evolution}

\author{
Alberto Luis López ${ }^{1}$ \\ Facultad de Estudios Superiores Acatlán, UNAM \\ (México) \\ Elvira López Rodríguez ${ }^{2}$ \\ Colegio de Ciencias y Humanidades Azcapotzalco, \\ UNAM (México)
}

Recibido: 21-11-18

Aprobado: 08-04-19

\section{Resumen}

En la segunda mitad del siglo XIX la filosofía positiva se consolidó como la corriente de pensamiento dominante en México, muchos pensadores la utilizaron como marco teórico para interpretar los acontecimientos pasados y proyectar el

\footnotetext{
${ }^{1}$ (alberto.luislopez@yahoo.com) Profesor de Filosofía en la Facultad de Estudios Superiores Acatlán, UNAM. Miembro del Sistema Nacional de Investigadores nivel I (Conacyt). Postdoctor en Filosofía Política de la modernidad por la Universidad de Québec en Trois-Rivières, Canadá (2016). Doctor en Filosofía con Mención Honorífica por la UNAM (2013). Ganador de la Medalla Alfonso Caso (2015) y del Premio Norman Sverdlin (2014). Realizó una estancia de investigación en el Trinity College de Dublín, Irlanda (2012). Maestro en Filosofía por la Universidad de Barcelona (2008) y Licenciado en Filosofía por la Universidad de Salamanca, España (2006). Sus áreas de especialización son: Berkeley, Locke, Filosofía moderna (epistemología, ontología, religión), Filosofía novohispana y mexicana. Sus áreas de competencia son: Filosofía de la Ilustración, Hermenéutica, Romanticismo alemán, Historia de la Modernidad y Postcolonialismo en México.

Es miembro de diversas sociedades académicas. Dictaminador de libros en universidades mexicanas y en revistas científicas indexadas. Ha publicado varios artículos especializados en revistas arbitradas e indexadas, tanto nacionales como extranjeras, y en libros colectivos.

${ }^{2}(\dagger)$ Profesora fundadora del Colegio de Ciencias y Humanidades Azcapotzalco (CCH-A), UNAM. Obtuvo la Cátedra Especial Mtro. Eduardo Blanquel Franco en 1991 y 1992 y dictó decenas de cursos y seminarios en distintas instituciones académicas tanto públicas como privadas. Obtuvo su Maestría en Historia de México y su Licenciatura en Historia (con especialidad en Historia de Asia), ambas por la Facultad de Filosofía y Letras de la UNAM. Entre sus libros destacan: El parámetro cronológico, México, ANUIES, EDICOL, 1977, 2 vols.; Historia Universal Moderna y Contemporánea I, CCH UNAM, 1998; México, su proceso histórico. De Oasisamérica a la República Restaurada, México, UNAM 2000 (vol. 1), 2001 (vol. 2). Publicó decenas de artículos tanto de opinión como académicos en distintas revistas del país. Sus áreas de investigación eran: Historiografía, Interdisciplinariedad, Dramaturgos mexicanos contemporáneos, Vida cotidiana en México (de 1940 a 1970) e Historia de México.
} 
futuro de la nación. Por su análisis, explicación e interpretación de la historia nacional México: su evolución social es la obra culminante del positivismo mexicano, pero para sorpresa nuestra ha sido poco estudiada por los especialistas, de ahí que sea necesario recuperarla. En este artículo nos damos a esa tarea y para ello nos enfocaremos en analizar el método de investigación que emplea la obra así como el papel que cumple la historia dentro de la misma. Con ello se busca contribuir a los estudios sobre el positivismo mexicano al abordar, en una obra crucial, algunos de sus aspectos metodológicos, históricos y filosóficos.

Palabras-clave: positivismo, historia, evolución social, progreso, organicismo, método, porfiriato.

\begin{abstract}
In the second half of the nineteenth century the positive philosophy was consolidated as the dominant current of thought in Mexico, many thinkers used it as the theoretical framework to interpret past events and project the future of the nation. Because of its analysis, explanation and interpretation of the national Mexican history México: su evolución social is the culminating work of Mexican positivism. To our surprise, the work has been little studied by scholars hence it is necessary to recover it. In this article we want to do that task and for that we will focus on analyzing the research method used in the work as well as the role played by history within it. The aim then is to contribute to studies on Mexican positivism by approaching, in a crucial work, some of its methodological, historical and philosophical aspects.
\end{abstract}

Key-words: Positivism, History, Social Evolution, Progress, Organicism, Method, Porfiriato.

\title{
Introducción
}

Algunas de las grandes preguntas que la historiografía ha intentado contestar a lo largo del tiempo, desde Heródoto (2016) hasta Koselleck (2001), han sido ¿Qué es la Historia? ¿Cómo se construye? ¿Para qué sirve? ¿Cómo entender los sucesos pasados? ¿Hay un decurso histórico interpretable? Las respuestas a estas interrogantes han sido muy variadas, por ser resultado , como deja entrever Braudel $^{3}$, de factores tales como i) la época en la que vive quien da la respuesta, ii) sus intereses personales, iii) su formación ideológica

${ }^{3}$ En la lección inaugural del $1^{\circ}$ de diciembre de 1950, titulada "Las responsabilidades de la historia", Braudel afirma: "porque siempre ha dependido, en su ser y en sus transformaciones, de condiciones concretas. La historia es hija de su tiempo". (Braudel 1970: 19). 
o posición política o iv) la 'moda intelectual' imperante. Un ejemplo de las muchas respuestas que se han dado a preguntas como las antes mencionadas es la monumental obra México: su evolución social. Esta obra, pensada como una interpretación del desarrollo histórico de la nación mexicana a partir de las herramientas teóricas y metodológicas de la doctrina positivista, en sus diversas vertientes, bien puede ser considerada la obra cumbre de la historiografía porfirista, y ello tanto por sus postulados como por su consistencia teórica. Por esto, es decir, por ser una obra central dentro de la historiografía mexicana -aunque para sorpresa nuestra ha sido poco estudiada- y porque asumimos que a través de ella se dará un mejor conocimiento del positivismo en México, decidimos hacerla nuestro objeto de estudio; sin embargo, dado que se trata de una obra monumental, para este artículo nos enfocaremos sólo en algunas de sus partes y en dos aspectos puntuales: i) el método de investigación que se emplea en ella y ii) la manera como se retrata y/o concibe la historia.

\section{Estructura y contexto de México: su evolución social}

Dado el poco estudio que ha merecido la obra que nos ocupa creemos importante contextualizarla. México: su evolución social ${ }^{4}$ fue publicada durante el 'porfirato', es decir, durante el periodo de gobierno del presidente Porfirio Díaz (1877-1911) y en el contexto de la llamada 'política científica' de corte positivista. Desde su planeación fue pensada como una obra única, por eso fue financiada por la Secretaría de Hacienda y Crédito Público (encabezada en aquel momento por José Yves Limantour) y publicada por el importante editor Santiago Ballescá. Su objetivo aparece claramente en el contrato entre el editor y la Secretaría de Hacienda: "Dar a conocer en el país y en el extranjero, la importancia de los progresos que México ha conquistado en todos los ramos del saber y de la actividad. [...] La obra será publicada con todo el lujo correspondiente a su importancia y en la ilustración se emplearán los procedimientos más modernos y perfectos en la encuadernación y hará grabar el editor Ballescá una plancha de lujo; la obra comprenderá tres ediciones: una en idioma castellano, otra en francés y en inglés la tercera" (Cfr. Sierra 2005, I: xxviii). La obra no fue creada para elogiar al régimen de Díaz, aunque reconoce las condiciones de desarrollo propiciadas por su gobierno (Covarrubias 2010: 236), sino que, paradójicamente, pretendía limitar sus atribuciones al hacer un análisis de todo el pasado nacional, incluido su régimen.

\footnotetext{
${ }^{4}$ El título completo es: México: su evolución social: síntesis de la historia politica, de la organización administrativa y militar y del estado económico de la federación mexicana; de sus adelantamientos en el orden intelectual; de su estructura territorial y del desarrollo de su población, $y$ de los medios de comunicación nacionales e internacionales; de sus conquistas en el campo industrial, agricola, minero, mercantil, etc., etc.
}

Araucaria. Revista Iberoamericana de Filosofia, Politica, Humanidades y Relaciones Internacionales, año $21, \mathrm{n}^{\circ} 42$. Segundo semestre de 2019. Pp. 85-107. ISSN 1575-6823 e-ISSN 2340-2199 doi: 10.12795/araucaria.2019.i42.05 
Se publicó en la Ciudad de México y fue dividida en dos tomos pero en tres volúmenes. El primer tomo se dividió en dos volúmenes, el primero publicado en 1900 y el segundo en 1902, mientras que el segundo tomo (un único volumen) apareció en 1901. Consta de dieciséis partes temáticas que tratan asuntos tan diversos como el territorio, la ciencia, la evolución mercantil, la literatura o la educación nacional. Aunque no hay una estructura clara ni bien definida, pues cada capítulo puede revisarse con independencia del resto, eso no significa que la obra no tenga unidad; de hecho, presenta un sentido de totalidad y eso se debe en gran medida a que fue dirigida por un solo individuo: Justo Sierra. Junto con Sierra colaboraron en el equipo editor catorce personas, aunque los autores de los artículos fueron sólo trece ${ }^{5}$, nacidos todos entre 1839 y 1873 y originarios de distintos estados de la república mexicana, lo que enriqueció la publicación al darle una perspectiva amplia y diversa sobre la realidad nacional (Flores 1983: $41 \mathrm{ss)}$ ). Los trece autores participantes fueron los abogados Manuel Sánchez Mármol, Julio Zárate, Genaro Raigosa, Miguel S. Macedo, Pablo Macedo, Ezequiel A. Chávez, Jorge Vera Estañol y Justo Sierra; los ingenieros Agustín Aragón y Gilberto Crespo y Martínez; el médico Porfirio Parra; el periodista Carlos Díaz Dufoo y el general Bernardo Reyes.

Debemos recordar que México: su evolución social no fue la primera obra de su tipo y, por lo mismo, hubo textos que influyeron decisivamente en su planeación. Éstos fueron 1) el Diccionario universal de historia y geografía (1853-1856) en 10 tomos $^{6}$; 2) Algunas ideas sobre la historia y manera de escribir la de México (1865) de Manuel Larráinzar73 3) Estudios sobre la historia general de México (1875-1877) de Ignacio Álvarez en 5 volúmenes; 4) Historia de México (1876-1882) de Niceto de Zamacois en 20 volúmenes; 5) History of Mexico (1883-1887) de Hubert H. Bancroften en 14 volúmenes; 6) México a través de los siglos (1884) de Vicente Riva Palacio ${ }^{8}$ en 5 tomos y 7) "México social y político: apuntes para un libro" (1889) de Justo Sierra. Las dos últimas obras fueron especialmente influyentes para la obra que nos ocupa: la primera, i.e., la enciclopedia dirigida por el general Riva Palacio, fue importante por i) la información detallada, precisa y exhaustiva que brindó sobre el país; ii) la periodización que hizo de la historia de México en época prehispánica, Colonia, Independencia, México independiente y Reforma; iii) el

\footnotetext{
${ }^{5}$ Colaboraron quince personas aunque sólo trece como autores. Emilio Pardo (jr.) y Eduardo Zárate fueron quienes no colaboraron con ningún texto.

${ }^{6}$ El Diccionario tuvo como colaboradores a José María Lafragua, Guillermo Prieto, Manuel Payno, Francisco Zarco, Joaquín García Icazbalceta y Manuel Orozco y Berra.

${ }^{7}$ Larráinzar manifiesta en su obra una actitud claramente positivista, al subrayar la necesidad de escribir una historia general de México no limitada a una época (prehispánica, colonial o de Reforma) y que esté regida por un plan rector que dé orden a partir de información seleccionada y basada en datos precisos. (Larráinzar 1992: 153 ss).

${ }^{8}$ Además de Riva Palacio participaron como autores los historiadores Alfredo Chavero, Juan de Dios Arias, Enrique de Olavarría y Ferrari, José María Vigil y Julio Zárate. (Cfr. Clark 2005: 357-362).
} 
interés de escribir una historia nacional; iv) la concepción del tiempo histórico lineal y continuo; v) haber utilizado el método positivo y abordado las teorías de la evolución. En cuanto al texto de Sierra, se trató de un ensayo que analizó temas etnográficos, demográficos, sobre la colonización o la historia política mexicana y delimitó los principios fundamentales de la política científica del momento, lo que sirvió de base y marco conceptual de la obra que él mismo coordinó años después.

A pesar de no ser la primera obra de su tipo, México: su evolución social superó a las que le antecedieron y se convirtió en la recopilación historiográfica más importante del porfiriato. Por eso el historiador Álvaro Matute ha argumentado que es un documento historiográfico e ideológico invaluable, ya que contiene "el credo fundamental del porfiriato" así como otros elementos influyentes para la Revolución mexicana. Lo considera "la más completa y sistemática elaboración de la ideología del grupo de los 'científicos', complementada con las expresiones de autores ajenos a él, pero de alguna manera coincidentes en muchos puntos de vista con los ideólogos porfirianos". (Cfr. Moya López 2003: 7). Para Matute, además, la obra tiene un valor científico incuestionable porque se trata "del primer trabajo serio en el que se aborda de manera temática la realidad social, económica, política y cultural de México" (Idem).

\section{El positivismo de México su evolución social}

Antes de hablar sobre el enfoque positivista de la obra en cuestión, podemos decir a grandes rasgos que la filosofía positiva surgió como "una reacción contra el idealismo [...] la bandera que enarbolará será la recuperación del hombre concreto, con sus sentidos, apetitos, sentimientos y pasiones; [busca] el rescate de la individualidad y, con ella, la comprensión total del proceso histórico" (Ortega y Medina 1980: 41). Más específicamente, esta filosofía surgió como reacción contra aquellas posiciones religiosas, filosóficas, políticas e incluso científicas que no fundamentaban sus juicios ni sus conclusiones en datos y constataciones empíricas. Por eso criticó que las interpretaciones del mundo, del tipo que fueren, emplearan "palabras a las que no corresponde ninguna experiencia. [...] El positivismo critica, por tanto, permanentemente tanto las interpretaciones religiosas del mundo como la metafísica materialista, y se esfuerza por encontrar un puesto de observación libre de todo presupuesto metafísico" (Kolakowski 1988: 22). Esta actitud constituyó el punto de partida

\footnotetext{
${ }^{9}$ Los llamados 'científicos' fueron personajes influyentes del régimen porfirista, destacan Francisco Bulnes, Emilio Pimentel, Joaquín Casús, Ramón Corral, José Yves Limantour, Miguel S. Macedo, Pablo Macedo, Emilio Rabasa, Enrique Creel y Justo Sierra.
} 
de la filosofía positiva, la cual no se limitó a un interés teórico sino que también tuvo un interés práctico, por eso buscó reformar la organización social desde una perspectiva científica basada en un enfoque empirista, para lo cual consideró indispensable hacer primero "una reforma de las ciencias y del pensamiento" (Ibidem: 68).

Los intelectuales porfiristas mexicanos del siglo XIX asumieron como suyos los postulados de la filosofía positiva, pero comprendieron que el éxito de aplicarlos dependía de que pudieran ser adaptados "a realidades estrictamente mexicanas", como puntualiza Zea en El positivismo en México ${ }^{10}$. Esto fue precisamente lo que se intentó hacer durante la 'política científica' de finales del siglo XIX, que implementó el positivismo y su metodología, basada en fundamentos científicos y técnicos, a las realidades del país para intentar solucionar los problemas nacionales. Hay que decir que la incorporación en México de la política positiva, i.e., la mezcla de política y postulados científicos, se debió al periódico La Libertad (1878-1884), fundado entre otros por Sierra y quien lo dirigió entre mayo de 1878 y abril de 1880 . Este periódico fue importante porque defendió los derechos de la sociedad, el orden y la paz, y constituyó "el primer órgano del positivismo mexicano que aplicó los principios de dicha filosofía para proponer una serie de medidas políticas" (Saez 1986: 219) ${ }^{11}$. Además, introdujo la idea de que el bien general y colectivo debía imperar sobre el bien individual, ya que el individuo era parte de una categoría más amplia llamada sociedad, por lo que quedaba subsumido a ésta. Con ello se fue incorporando y consolidando la idea de que lo importante era hablar de colectividad (nación) y no tanto de individualidad, porque los grandes motores del progreso nacional no se enfocaban en la realización integral del individuo, sino en el desarrollo económico (Riguzzi, 2009), en la reorganización administrativa y en el fomento a la educación nacional bajo una perspectiva científica. Esta concepción terminó por ser la dominante en el México de finales de siglo, lo que explica por qué México: su evolución social presentó un carácter positivista al concebir, entre otras cosas, un sujeto de la historia no en términos individuales, sino en términos de fuerzas colectivas y grupos organizados. Esto es precisamente lo que expresa uno de los autores, Genaro Raigosa, en su artículo "La evolución agrícola":

${ }^{10}$ Zea señala: "La filosofía positivista de Augusto Comte, traída a México por Gabino Barreda, fue el principal instrumento de polémica ideológica de que se sirvieron los positivistas mexicanos en su lucha contra las doctrinas con las cuales se enfrentaron [...] Del comtismo se sacaron los principales conceptos utilizados por los positivistas de México. A estos conceptos se les dio un contenido propio de México" (Zea 1968: 38).

${ }^{11}$ Durante la dirección de Justo Sierra "el diario [La Libertad] mantuvo una actitud crítica hacia la administración porfirista” (Saez 1986: 218). Sierra defendió la tesis sostenida por la Unión Liberal, fundada en 1892, de que en México se había consolidado el orden y la paz a consecuencia de que el Partido Liberal, que promulgó la Constitución de 1857, se había vuelto un partido de gobierno; por tanto, más que fortalecer a la autoridad había que asimilar y aplicar los principios libertarios contenidos en la propia Constitución.

Araucaria. Revista Iberoamericana de Filosofia, Política, Humanidades y Relaciones Internacionales, año $21, \mathrm{n}^{\circ} 42$ Segundo semestre de 2019. Pp. 85-107. ISSN 1575-6823 e-ISSN 2340-2199 doi: 10.12795/araucaria.2019.i42.05 
El proceso evolutivo del organismo social ha llegado, por tanto, á una etapa en la cual las energías particulares de sus integrantes individuales reclaman la intervención del centro director, á fin de que la resultante de las fuerzas en ejercicio para satisfacer necesidades premiosas de conservación y prosperidad de la vida en conjunto, sean encaminadas por acción de la fuerza pública hacia la línea de contacto con el beneficio nacional (Sierra 2005, II: 45).

La impronta positivista de la obra se manifestó no sólo en el uso e incorporación de categorías positivas, sino también en la pretensión y búsqueda de un saber histórico que teniendo en cuenta el cuerpo social sirviera de orientación al poder. Debemos decir, sin embargo, que salvo el caso de Sierra no es posible identificar plenamente al grupo positivista que participó en la obra con el grupo de los 'científicos', pues mientras éstos eran, en términos generales, profesionistas con cierta inclinación al positivismo, muchos de aquéllos eran positivistas convencidos que incluso rayaron en la ortodoxia, como Porfirio Parra (discípulo de Gabino Barreda), Ezequiel A. Chávez o Agustín Aragón. No obstante, como no todos los autores fueron positivistas ortodoxos, ni contaban con la misma formación académica y teórica (por ejemplo, Raigosa y Reyes nunca tuvieron actividad docente ni académica mientras el resto sí), la obra presenta distintos alcances teóricos ${ }^{12}$. Esto se dio, además, porque sumado al positivismo de Comte, Stuart Mill, Spencer o Taine (Matute 1991: 2), algunos autores se nutrieron de corrientes tan diversas como el nacionalismo, el liberalismo (presente durante todo el porfiriato) y/o los ideales románticos, bien arraigados ya en el México de finales del siglo XIX. Ese eclecticismo se evidenció en las pocas referencias directas a las obras de Comte, Spencer o Mill, salvo las hechas por Sierra, Aragón, Parra, Chávez, Raigosa y los hermanos Macedo (Miguel y Pablo) ${ }^{13}$. Pese a esto, es posible afirmar que la mayoría de los autores, salvo Reyes y el enfoque liberal de Zárate, Vera Estañol y Sánchez Mármol, sostuvieron una postura positivista; de ahí que, por ejemplo, Chávez y Aragón (que en 1901 publicó la Revista positiva científica, filosófica social y política) se hayan preocupado, desde una postura más sociológica, por conocer y difundir el pensamiento de Comte, Mill y Spencer (sobre todo la parte lógica, moral y metodológica de sus obras), o que Parra y Miguel Macedo hayan sido socios de la 'Asociación Metodófila Gabino Barreda', fundada en 1877 y que formó la segunda generación de positivistas mexicanos (incluso Parra y Aragón crearon tiempo después la 'Sociedad Positivista', siendo Parra su primer director en 1900 (Alvarado 1989: 214).

\footnotetext{
${ }^{12}$ Según el nivel teórico alcanzado en sus ensayos agrupamos a los autores en tres grupos: el más avanzado estaría conformado por Sierra, Chávez y Aragón; el siguiente por Vera Estañol, Parra y Miguel Macedo, y el más inferior por Sánchez Mármol, Zárate y Reyes.

${ }_{13}$ Por ejemplo, hay algunas referencias al escrito de Spencer Industrial Institutions (1896), que conforma la última parte del tercer volumen de sus Principles of Sociology publicados entre 1874 y 1896 (Spencer 1966).
}

Araucaria. Revista Iberoamericana de Filosofia, Política, Humanidades y Relaciones Internacionales, año $21, \mathrm{n}^{\circ} 42$. Segundo semestre de 2019. Pp. 85-107. ISSN 1575-6823 e-ISSN 2340-2199 doi: 10.12795/araucaria.2019.i42.05 
En la obra que nos ocupa el positivismo también se manifestó en la adhesión implícita, admitida también por los liberales, al principio constitucionalista para la reforma política y social, de ahí que se asumiera, en concordancia con los 'científicos', el postulado central de la sociología de la época (consecuencia de la filosofía natural del siglo XVII) que sostenía que, dado que la sociedad era un organismo en evolución que debía estudiarse históricamente, los fenómenos sociales eran fruto de leyes inmutables que podían ser descubiertas para prever la acción política. Esa concepción, debemos subrayar, prevaleció en los tres volúmenes coordinados por Sierra.

\section{El método histórico positivista: una investigación científica}

En cuanto al método de investigación empleado en la obra, podemos decir -como hemos adelantado- que pese a su distinta formación académica es palmario que la mayoría de ellos se sirvió de la metodología científica de corte positivista. Ésta era la herramienta en boga, considerada la más eficiente, rigurosa y exacta para estudiar los hechos sociales. En particular, como la filosofía positiva reconocía la importancia de la historia, a la que estudiaba como historia positiva, esto es, buscando alcanzar un conocimiento histórico quasi científico de los sucesos pasados, los participantes hicieron suya la historia positiva; gracias a ésta podían detectar la evolución histórica de la nación mexicana y mostrar cómo las bases de la cultura mexicana, según el periodo histórico en el que se encontraba, propiciaban y a la vez se correspondían con los avances que iba teniendo el país ${ }^{14}$.

El método histórico positivista utilizado tuvo como eje motor dos operaciones propias del positivismo comteano: el "análisis" y la "crítica". Por medio del 'análisis' se examinaron las fuentes en su aspecto externo, precisando fechas, autores, autenticidad de la información, de las fuentes, etc. A través de la 'crítica' se estableció una valoración sobre qué partes podían ser utilizadas y cuáles no, para posteriormente implementar clasificaciones y relacionar unos hechos con otros. En términos generales podemos decir que la forma en la que los autores se acercaron a sus temas fue comparando, comprobando, describiendo y explicando la información recabada, con el propósito último de prever prospectivamente el devenir de los acontecimientos que estudiaban. Esto era especialmente importante porque lo que buscaban al describir era prever el

\footnotetext{
${ }^{14}$ A finales del siglo XIX, como consecuencia de las Leyes de Reforma, muchos asumían que para acabar con los pilares del antiguo régimen colonial (la religión y la Iglesia) y sentar las bases de una nación moderna había que instaurar el laicismo. Esta idea impulsó en parte la implementación del sistema positivista, cuya visión científica del mundo representaba mejor el progreso. Así, el laicismo, impulsado por parte de la cúpula porfirista, fue un factor que impulsó la introducción del positivismo en México.
} 
futuro con miras a un mejoramiento constante. Esto último, que no era sino un anhelo de progreso, hizo pensar a los autores que los únicos capaces de guiar a la humanidad hacia algo mejor eran aquellos que se servían de la metodológica de los planteamientos científicos. De esto se desprende que la relación pasadofuturo era muy importante, porque para prever había que conocer lo anterior; por eso la mayoría de los autores asumieron como labor propia el estudio del pasado, al que entendían como un conjunto de hechos cognoscibles (por las fuentes) que servían para hacer análisis prospectivos.

En cuanto a las fuentes, debemos reconocer que aunque no todos los autores eran positivistas ortodoxos todos compartían el afán por documentar, por lo que consideraron imprescindible fundamentar bien sus escritos. En relación a esto, los colaboradores utilizaron básicamente fuentes documentales aunque muchas veces no las citaron expresamente (lo que no era privativo de ellos, sino que era una constante en las obras de la época). Pese a esto, es de valorar su honestidad al reconocer sus propias limitaciones, ya que desde el primer volumen, en la página dedicada "Al lector", admiten que "no osamos suponer que de nuestros estudios puedan inferirse previsiones exactas" (Sierra 1900-1902: 5). Esta afirmación honesta no tiene que ver con su anhelo prospectivo, sino con la falta de estudios de caso y de estadísticas completas y bien organizadas, hecho que les impidió establecer con mayor exactitud los factores históricos, sociales y políticos de la evolución mexicana.

Pese a lo anterior, en la obra se reprodujo la actitud de los historiadores positivistas, pues mientras unos autores se empeñaron en la precisión y en el principio de la demostración de los hechos, cayendo en el detalle y dejando de lado la búsqueda y formulación de leyes (haciendo por ello estudios puramente monográficos), otros se preocuparon por las relaciones que entretejen y dan sentido a los hechos, encontrando conexiones y regularidades en el proceso histórico. Estas dos actitudes convergieron en la obra y quizá abonen a la explicación de los distintos niveles teóricos de los artículos, pues hubo algunos (como el de Sánchez Mármol) bien documentados y hasta prolijos en referencias, aunque sólo dieron razón de la "evolución" de los temas; otros (como el de Zárate o Reyes) ni siquiera mostraron sus fuentes de consulta, mientras otros (como el de Sierra o Chávez) intentaron encontrar los hilos conductores del proceso histórico que estudiaban, y por lo mismo estuvieron orientados a entender la formación y el complejo desarrollo de la nación mexicana.

El hecho de que la obra haya sido organizada en partes o capítulos temáticos desarrollados cronológicamente, acorde a las grandes etapas de la historia nacional, refleja el peso de la concepción organicista fruto de la influencia positivista y de las teorías de la evolución social, sobre todo de Herbert Spencer (Moya López 1999: 134 ss). Éste, al equipar el progreso social con el progreso biológico y extraer deducciones morales de la evolución, 
entendió el progreso como espontáneo y automático, por lo que la acción y el esfuerzo humanos quedaban relegados a una simple interferencia en las leyes biológicas de la naturaleza. Esta idea, asumida por muchos de los autores, aunque sus interpretaciones sobre Spencer no hayan sido del todo apegadas al pensamiento del inglés (Priego, 2012), muestra que la concepción organicista spenceriana permeó sobremanera la configuración y metodología de la obra, al entender -como planteó Aragón en "El territorio de México y sus habitantes" (Sierra 2005, I: 7ss) - a la sociedad, y por ende a la nación, como una especie de "organismo" social, esto es, como un ser vivo, complejo, relacionado entre sí y con su "medio"; por eso, para estudiar ese organismo (México) había que tener una visión amplia y completa, lo que se lograba articulando temáticamente (orgánicamente) los diversos conocimientos que hasta entonces se tenían. "Si las sociedades eran organismos, la fase anárquica anterior a 1877 era lo que los sociólogos llamaban incapacidad orgánica que había sido paulatinamente remontada por la adaptación de las condiciones naturales de la evolución y el progreso" (Moya López 2003: 51).

Si bien es cierto que la obra fue resultado de una historiografía influida por las ciencias naturales, especialmente la biología, y por los sistemas sociológicos de corte positivista, y a pesar de que los autores utilizaron como criterio metodológico de verdad el estatuto científico de las ciencias de la naturaleza, debemos aclarar que no presenta una interpretación positivista ortodoxa; aunque es verdad que la dedicatoria "Al lector" menciona que la obra pretende mostrar las señales del crecimiento de la nación o, lo que es lo mismo, "de toda evolución orgánica", y para ello -aclara- será necesario acercarse a los hechos sin "adulterar la verdad", porque sólo a partir de éstos:

[se podrá] mostrar á grandes, pero característicos rasgos, cómo, después de una lenta y penosa gestación, esta Sociedad [mexicana] se desprendió del organismo colonial y fué, por un acto supremo de su voluntad, y cómo, tras una existencia irregular y tumultuosa, ha llegado á normalizar una labor vital de asimilación de los elementos sustanciales de la civilización en general sin perder las líneas distintivas de su personalidad (Sierra 2005, I: 5).

La cita anterior contiene términos como 'gestación', 'organismo', 'vitalidad' y 'civilización', lo que pone de manifiesto no sólo la concepción positivista de la obra, sino, sobre todo, su metodología histórico-cientificista. Entre líneas, además, puede leerse la referencia a la acción combinada de la sociedad y el Estado, por ello se presuponía que del conjunto de las diversas transformaciones suscitadas en el país resultaba una evolución, es decir, un paso ascendente de lo inferior a lo superior. Esta evolución se denominó "evolución social", porque abarcaba las principales manifestaciones de la actividad humana de la nación mexicana; por eso cada 'parte' del libro representó un 
subsistema con funciones específicas integradas al todo, es decir, al organismo social mexicano, pero con la capacidad de responder a aspectos diferenciados. Eso explica por qué se describieron los diferentes campos como parte de una entidad mayor, y por qué fueron explicados cada uno en su proceso evolutivo particular según una secuencia histórica.

Es cierto que el método histórico positivista tuvo sus limitantes al llevar a la historiografía, por momentos, a la acumulación detallada de datos, pero también generó buenos frutos al recordarle a la humanidad la importancia del pasado. Esto fue lo que sucedió con la obra coordinada por Sierra, que al recuperar el pasado se preocupó por el presente y el futuro, lo que la encaminó a la labor de construir una identidad nacional que fungiese como soporte de la unidad de la nación (interés que se mantuvo latente varias décadas después de publicada la obra ${ }^{15}$ ).

\section{Del método histórico a la concepción de Historia}

En cuanto a la concepción de historia presente en México: su evolución social, lo primero que debemos decir es que cada autor definió la historia de distinta forma. Por ejemplo, en "Las Letras Patrias" Sánchez Mármol la concibió así: “¿La historia es literatura? Indudablemente que sí, cuando por historia se entiende no el simple relato de los sucesos acaecidos en determinado periodo de la vida de un pueblo ó de una sociedad [... que esa es la crónica. La historia es literatura cuando el que la escribe se apodera de los acontecimientos y los estudia para reconstruir [...] una verdad de conjunto, con fragmentos de verdad" (Sierra 2005, II: 643). Por su parte, en "La evolución minera" Crespo entendió la historia de manera optimista, como una ciencia sujeta a leyes que permite la explicación del pasado y la prevención del futuro, mientras en "La ciencia en México" Parra la concibió en los términos siguientes:

Hoy se admite para el hombre colectivo, como para el hombre individual, un desarrollo, una evolución, un conjunto armónico de leyes, que producen modificaciones predeterminadas, cambios previsibles, y si, bebiendo en las abundosas y sanas fuentes del nuevo concepto sociológico, acaso pierda la historia aquella majestad que le imprimieron los Tácito y los Suetonio, ó aquella hermosa sencillez que debió á Tito Livio, ganara de fijo en amplitud de miras, en exactitud de juicios, y en la abundancia y oportunidad de sus previsiones. Ese concepto de sociedades humanas, gradual y cuidadosamente elaborado por

15 Ejemplo de la importancia del asunto de la identidad fue la aparición del Grupo Filosófico Hiperión, formado en 1949 en la Facultad de Filosofía y Letras de la Universidad Nacional (UNAM) bajo la tutela de Samuel Ramos y José Gaos. El Grupo conformado por Emilio Uranga, Luis Villoro, Leopoldo Zea, Jorge Portilla, Ricardo Guerra, Sánchez MacGregor, Reyes Nevares y Fausto Vega. (Véase, Zea 2001: X-XI). 
la ciencia, resuelve á éstas en un conjunto complejo de elementos íntimamente asociados en el tiempo y en el espacio (Sierra 2005, II: 417-18).

A pesar de no haber en la obra una definición unívoca de historia podemos colegir que para la mayoría de los autores, en gran medida por influencia del positivismo, ésta era una ciencia que servía de base a las especulaciones sociales. Esta concepción se debía a que, en mayor o menor medida, retomaron la postura de Comte, para quien la historia tenía un objeto de estudio propio, un método y una finalidad que respondía a leyes de observancia universal. Su objeto de estudio versaba sobre la evolución de la realidad social, de ahí que la historia incidiese en aquélla al dar cuenta de su evolución. "Comte afirmaba que ningún fenómeno podría ser verdaderamente conocido a menos que fuese situado en el tiempo, con sus antecedentes y sus consecuencias, la historia se convierte en una dimensión de la naturaleza" (Suárez 1972: 109). Para el positivismo comteano, la historia rescataba los hechos con la mayor objetividad posible para entender cómo éstos transformaban a la sociedad. Esta fue, de hecho, la noción de historia que compartió el coordinador de la obra desde 1888 al pronunciar una alocución a niños de primaria: "decir cómo ha sucedido esto, cómo los pueblos, desapareciendo unos y sobreviviendo otros, han pasado del estado salvaje al que tienen hoy, es lo que se llama historia" (Sierra 1984a: 200). Estas palabras de Sierra están impregnadas de la idea de progreso y ya contienen en ciernes la noción de cambio y devenir natural que se verá plasmado, más palmariamente, en 1894 en su "Catecismo de Historia Patria", donde el pensador mexicano arguyó que la sociedad se transformaba de manera semejante a como lo hace un organismo vivo: "un ser vivo, por tanto crece, se desenvuelve y se transforma; esta transformación perpetua es más intensa al compás de la energía interior con que el organismo social reacciona sobre los elementos exteriores para asimilárselos y hacerlos servir a su progresión" (Ibidem: 362).

Ruiz (1987) apunta que en esa época, finales del siglo XIX, la concepción de historia se entremezclaba con elementos de la biología, porque se entendía que la historia estudiaba la sociedad como si se tratase de un ser vivo, de un "organismo social", con órganos (subdisciplinas) especializados que se distribuían el trabajo quasi fisiológicamente para obtener mayor eficiencia ${ }^{16}$. Esta vinculación entre historia y biología, asumida y aplicada en México: su evolución social, permitió analogar un organismo vivo con la sociedad y afirmar que si la parte más importante del primero la realizaba el cerebro, en el segundo la efectuaba el Estado. Esta concepción -por cierto- vino de la lección

\footnotetext{
${ }^{16}$ Rosaura Ruiz argumenta en su libro (1987) que los positivistas mexicanos retomaron la teoría de la evolución de Darwin y los planteamientos de Spencer, manejando con ello un darwinismo social que, en gran medida, orientó sus planteamientos sobre la sociedad. Es interesante contrastar esta tesis con lo planteado por Natalia Priego en un artículo más reciente (2012).
}

Araucaria. Revista Iberoamericana de Filosofia, Política, Humanidades y Relaciones Internacionales, año $21, \mathrm{n}^{\circ} 42$ Segundo semestre de 2019. Pp. 85-107. ISSN 1575-6823 e-ISSN 2340-2199 doi: 10.12795/araucaria.2019.i42.05 
48 del tomo cuarto del Cours de philosophie positive, donde Comte argüía que la sociedad debía entenderse en dos niveles: 1) el "estático", que planteaba la estructura propia de la sociedad, y 2) el "dinámico", que daba cuenta de las etapas recorridas por la sociedad ${ }^{17}$. De esto se desprendía que mientras la sociología debía estudiar la estructura de la sociedad, la historia debía enfocarse en los hechos por los que había pasado esa sociedad en su "evolución".

En distintos grados, todos los autores de México: su evolución social retomaron para sus artículos los planteamientos comteanos, por eso Sierra argumentó en "Historia política" que la historia política hacía referencia a la evolución mental y social de una sociedad, lo cual era fruto del triunfo de la concepción histórico-liberal, de los gobiernos republicanos y de los hombres que al tomar decisiones (políticas, económicas y/o sociales) ponían en sus manos el destino de la sociedad. Otro ejemplo, además de Sierra, es el de Aragón, quien en su artículo sobre el territorio señala que "Antes de conocer el estado dinámico de una sociedad ó su progreso, debe conocerse en su estado estático ó en aquellos elementos que son causa ó antecedente de su evolución" (Sierra 2005, I: 8). Debemos recordar que la relación entre historia, biología y sociología, tan propia del positivismo, fue asumida por Sierra desde 1888 en su mencionado escrito Elementos de Historia general, donde arguyó:

[los pueblos] nacen, crecen o se desarrollan y luego declinan y desaparecen transformándose, es decir, mueren, porque la muerte no es más que un cambio de forma o transformación [...] la humanidad ha ido avanzando en cada uno de ellos (los distintos pueblos); este avance quiere decir que ha nacido, crecido y desarrolládose, aún no le llega la vejez y está muy lejos de su muerte. Pues bien, a este hecho o fenómeno (retengamos bien esta palabra) que resulta de muchos otros hechos o fenómenos particulares, daremos este nombre: ley, porque es muy general, porque todos los hechos le están sometidos, y llamaremos a esta ley de la historia, la ley del desarrollo, o con una palabra adoptada por los sabios: la evolución. ([1888] 1984a: 287)

La 'evolución' a la que refiere Sierra en la cita está basada en la ley comteana de los tres estados (teológico, metafísico y positivo), enunciada en la Lección 1 del tomo primero del Cours como una prueba histórica de "la verdadera naturaleza y el carácter propio de la filosofía positiva" (Comte 1830: $2)^{18}$. En términos generales es posible afirmar que esta ley fue empleada por

\footnotetext{
17 En esa lección Comte argumenta: "el estudio estático del organismo social debe coincidir plenamente con la teoría positiva del orden, que no puede consistir más que en una correcta y permanente armonía entre las diversas condiciones de existencia de las sociedades humanas: lo mismo se ve, incluso con mayor claridad, que el estudio dinámico de la vida colectiva constituye necesariamente la teoría positiva del progreso social, que alejado de todo pensamiento inútil de perfectibilidad absoluta e ilimitada debe reducirse naturalmente a la simple noción de este desarrollo fundamental" (Comte 1839: 320-321).

${ }^{18}$ Casi al inicio de esa primera lección Comte señala: "Esta ley consiste en que cada una de nuestras
} 
todos los autores de México: su evolución social, con el objetivo de periodizar las fases de la evolución o cambio en sus respectivos temas, pero sobre todo para explicar el proceso histórico que -según ellos- guiaba al país hacia el "progreso" (lo que constata que la idea de evolución social de la nación mexicana fue el principio rector de la obra que nos ocupa).

Nuevamente Sierra es quien mejor ejemplifica la periodización de la historia de México a partir de bases comteanas, pues dividió su artículo "Historia política" en tres períodos que recuerdan los tres estados de la ley de Comte: 1) Las civilizaciones aborígenes y la conquista, 2) La colonia y la independencia y 3) La república, dividida a su vez en tres etapas: 3a) La anarquía, 3b) La reforma y 3c) La era actual. En su interpretación positivista de la historia de México, Sierra considera que el estado teológico está representado en un primer momento por las "civilizaciones aborígenes", que pasaron del fetichismo al politeísmo, momento en que se detuvo su proceso evolutivo. Este primer momento es seguido por la conquista y colonización, que constituye la última fase de la etapa teológica. El movimiento de independencia significa el paso a la fase metafísica y un salto adelante en la evolución social de los mexicanos, pues sustituye las explicaciones religiosas de las cosas por ideas abstractas que buscan ordenar el ámbito social a partir del propio individuo, de sus leyes y de su capacidad de organización. En esta etapa de transición entre la infancia y la madurez de la sociedad, Sierra considera que el liberalismo doctrinario de la primera mitad del siglo XIX se transformó en un liberalismo político con la Constitución de 1857, sentando con ésta las bases para ingresar a la etapa de madurez positiva.

Podemos afirmar sin ambages, a partir de los propios artículos, que en la obra prevalece una concepción científico-positivista de la historia, donde lo más importante es dar razón de la evolución del organismo social y al ser eso tarea de la historia ésta se convirtió en la columna vertebral de los distintos ensayos, al dar cuenta de la evolución de los grandes problemas nacionales. Es por eso que la obra constituyó un magnífico acervo de los distintos conocimientos que se tenían hasta entonces del desarrollo del país.

La obra fue heredera para un número importante de autores, de una segunda vertiente historiográfica [además de la 'historiografía erudita'] que bien se podría nombrar tempranamente como positivista y que abrió la discusión sobre

principales concepciones, cada rama de nuestros conocimientos, pasa sucesivamente por tres estados teóricos diferentes: el estado teológico o ficticio, el estado metafísico o abstracto y el estado científico o positivo. En otros términos, el espíritu humano, por su naturaleza, emplea sucesivamente en cada una de sus investigaciones tres métodos de filosofar, cuyos caracteres son esencialmente distintos e, incluso, radicalmente opuestos: primero, el método teológico, a continuación el método metafísico y, por fin, el método positivo. De aquí tres tipos de filosofía o de sistemas generales de concepciones sobre el conjunto de los fenómenos, que se excluyen mutuamente: el primero es el punto de partida necesario de la inteligencia humana: el tercero su estado fijo y definitivo; el segundo está destinado únicamente a servir de transición" (Comte 1830: 3-4).

Araucaria. Revista Iberoamericana de Filosofia, Política, Humanidades y Relaciones Internacionales, año $21, \mathrm{n}^{\circ} 42$ Segundo semestre de 2019. Pp. 85-107. ISSN 1575-6823 e-ISSN 2340-2199 doi: 10.12795/araucaria.2019.i42.05 
el estatus científico de la historia. En esta línea de pensamiento se asumió que la ciencia de la historia debía tender hacia un conocimiento objetivo del pasado, lo cual suponía desaparecer de tajo los problemas que implican la relación de temporalidad entre el sujeto presente y su objeto pasado, la dimensión de la interpretación, las implicaciones de la subjetividad, así como el problema del espacio social desde donde escribe el historiador. Una perspectiva como la anterior implicó además la representación lineal del tiempo, es decir, que los acontecimientos podían ser conocidos en sí mismos como algo dado, como objetos equiparados epistemológicamente a los que figuraban en las ciencias naturales. El positivismo en la historiografía asumió, por tanto, que la verdad científica tenía un sustento basado en lo empírico, en la observación de los hechos, en este caso a través del documento, el cual constataba lo sucedido (Moya López 2003: 19-20).

Es de destacar que en la obra se dejó de lado la historia de partidos (algo que ya había ocurrido parcialmente en la enciclopedia México a través de los siglos), la cual fue sustituida por una historia general con una concepción lineal y continua del tiempo, que pretendía abarcar a toda la nación desde sus orígenes, es decir, desde la antigüedad prehispánica hasta la etapa más actual. Los diversos periodos de la historia nacional fueron entendidos, cual organismo vivo, como parte de un proceso evolutivo que iba integrando a la nación y cuyo transcurso seguía las leyes inmutables del progreso (Cfr. Cosío Villegas[1949] 2004; Florescano [1980]). Los diversos artículos también muestran que no se concibió la historia como una descripción dominada por grandes hombres ni limitada a movimientos políticos, sino como un proceso orgánico que debía describir científicamente la evolución social (idea que -por cierto- ya aparece en las "Consideraciones generales" de la enciclopedia de Riva Palacio, donde se menciona que la humanidad se encuentra en un periodo científico que ha dado un nuevo giro al estudio y a los escritos de historia ${ }^{19}$ ).

${ }^{19}$ Dice Riva Palacio: "no es ésta [la historia] ya la simple narración de acontecimientos, ni el juicio más o menos acertado de los movimientos políticos y de la conducta de los hombres que han regido los pueblos o influido de alguna manera en sus destinos; altas consideraciones filosóficas sobre las evoluciones sociales y sobre la marcha y el progreso del espíritu humano, sobre el influjo de la ley de la herencia en el pasado y en el porvenir de una nación y sobre el estudio del complicado problema de la geografía política del mundo, investigaciones acerca de la relación que el territorio habitado y el medio vital tienen en los caracteres nacionales; éstas son en lo general las grandes cuestiones que van preocupando cada día más a los modernos escritores. La historia detallada y minuciosa de los sucesos y de las personas va separándose de la historia sin personajes, y aunque mutuamente prestándose auxilios y siéndose indispensables la una a la otra, es la segunda la que debe prestar positiva utilidad en lo porvenir, llevando por base las ciencias sociológicas y sirviéndoles al mismo tiempo a esas ciencias de centro y dirección" (Riva Palacio 1884, II: 898). 


\section{De la concepción de historia a la finalidad de la historia}

La última parte de este trabajo versa también sobre la historia, pero tiene que ver con el propósito de ésta, es decir, con la finalidad de los acontecimientos históricos. Para ello debemos remitirnos nuevamente a Comte, quien en la lección 47 del cuarto tomo de su Cours sostuvo: "la historia no ha dejado de tener un carácter esencialmente literario o descriptivo, y no ha adquirido una verdadera naturaleza científica, estableciendo una verdadera filiación racional en el curso de los acontecimientos sociales, de forma que permita, como para todo orden de fenómenos, y entre los límites generales impuestos por una complicación superior, una cierta previsión sistemática de su sucesión ulterior" (Lefebvre 1974: 239; Comte 1839: 282). De la cita se deprende que para el francés la función principal de la historia es prever el futuro, lo que no se logra mediante una premonición sino a partir del conocimiento objetivo que reporta el estudio científico del pasado. Éste ha comprobado, según la propia doctrina positivista, que el desarrollo de la humanidad ha pasado por los estados teológico y metafísico hasta arribar al positivo, caracterizado por el progreso material y mental de la sociedad ${ }^{20}$.

Como hemos dicho, esta tesis fue retomada por los autores de México su evolución social cuando asumieron que el país había pasado por diversas fases progresivas hasta llegar al periodo del general Díaz ${ }^{21}$, aunque -cabe mencionarno consideraron su gobierno como la culminación de la época positiva sino, más bien, como una "dictadura social" o una especie de "cesarismo espontáneo" (Sierra 2005, III: 433) ${ }^{22}$ que se había servido de la fuerza para imponer el orden en la nación. Si bien este orden era una condición indispensable para impulsar el verdadero progreso, de ahí la fórmula positivista Amor, Orden y Progreso ${ }^{23}$,

${ }^{20}$ En la lección 57 del sexto y último tomo del Cours se arguye: "La élite de la humanidad, después de haber agotado todas las fases sucesivas de la vida teológica, y aun los diversos grados de la transición metafísica, llega ahora al advenimiento directo de la vida plenamente positiva, cuyos principales elementos han recibido ya la necesaria elaboración parcial y no esperan más que su coordinación general para constituir un nuevo sistema social, más homogéneo y más estable que jamás pudo serlo el sistema teológico, propio de la sociabilidad preliminar." (Comte 1842: 519-20; Vázquez 1980: 141).

${ }^{21}$ En Catecismo de Historia Patria Sierra se pregunta si el gobierno de Díaz representa una nueva era. Su respuesta es categórica: "Sí, una era de paz, que ha durado bastante para esperar que ya no vuelvan a haber revoluciones sangrientas, que tanto mal han hecho a nuestra patria; y una era de mejoras materiales en que se han hecho más caminos de hierro de lo que hubiera nadie figurado hace veinte años; ellos han transformado el país y lo harán rico y poderoso más tarde. Esto se ha hecho en diversas administraciones del general Porfirio Díaz” (Sierra, 1984b: 420).

22 "Las dictaduras de hombres progresistas, que sean al mismo tiempo administradores inteligentes y honrados de los fondos públicos, suelen ser eminentemente benéficas en los países que se forman, porque aseguran la paz y garantizan el trabajo, permitiendo almacenar fuerzas a los pueblos. Pueden ser detestables en teoría, pero las teorías pertenecen a la historia del pensamiento político, no a la historia política, que sólo puede generalizar científicamente sobre hechos" (Sierra 2005, I: 203).

${ }^{23} \mathrm{La}$ frase aparece en el segundo volumen del Système de politique positive: "l'Amour pour principe, l'Ordre pour base, et le Progrès pour but' (Comte 1852: 65).

Araucaria. Revista Iberoamericana de Filosofia, Política, Humanidades y Relaciones Internacionales, año $21, \mathrm{n}^{\circ} 42$. Segundo semestre de 2019. Pp. 85-107. ISSN 1575-6823 e-ISSN 2340-2199 doi: 10.12795/araucaria.2019.i42.05 
el positivismo mexicano modificó la fórmula a partir de la Oración Cívica (1867) de Gabino Barreda y adoptó la frase de Libertad, Orden y Progreso (Barreda 2005: 40). La incorporación del término 'libertad' habla de cómo se integró la herencia liberal a la política positiva mexicana, pero también de cómo se sometió la libertad al orden y a las leyes de la sociedad, esto es, al interés social y de la nación y a los requerimientos del progreso. El nuevo lema mexicano también representó una forma de entender al individuo, que tenía libertad de pensar lo que quisiera pero debía comportarse acorde a los objetivos de la sociedad en su conjunto. De esa manera se buscó -aunque pocas veces se logró- respetar la libertad individual sin menoscabo del interés social.

A partir de lo anterior surge un aspecto sobre la finalidad de la historia que no se había considerado antes, el cual tiene que ver con el anhelo de que la "evolución social" no consistiera sólo en el progreso material, alcanzado en parte con el gobierno de $D_{1}{ }^{24}{ }^{24}$, sino que también conllevara alcanzar la libertad, entendida como el punto más alto del progreso humano. Esto es lo que indica Sierra en "Historia política" al decir que "Toda la evolución social mexicana habrá sido abortiva y frustránea si no llega a ese fin total: la Libertad" (Sierra 2005, III: 434). La finalidad de la historia iba más allá de prever los futuros acontecimientos, tenía que ver sobre todo con alcanzar la libertad. Conviene preguntarse, sin embargo, de qué tipo de libertad estaban hablando. La respuesta la podemos dar con la segunda parte del escrito de Sierra, en el apartado "La era actual", donde se considera que en México había 'evolución social' mas no 'evolución política', pues el gobierno de Díaz, autoritario mas no despótico ni inconstitucional, había conseguido varios logros (hacer la paz, dirigir la transformación económica, extinguir los cacicazgos y tiranías locales e impulsar la evolución social) pero lo había hecho en detrimento de los derechos políticos, es decir, de la evolución política. Faltaba, entonces, impulsar las libertades políticas porque con ello se impulsaría también el progreso material, pero esto sólo se conseguiría -según Sierra y la mayoría de los autores- a través de la educación, por ello la consideraban la obra más importante y, sin embargo, la que faltaba por desarrollar: "Nos falta producir un cambio completo en la mentalidad del indígena por medio de la escuela educativa. Ésta, desde el punto de vista mexicano, es la obra suprema que se presenta á un tiempo con caracteres de urgente é ingente. Obra magna y rápida, porque ó ella ó la muerte" (Sierra 2005, III: 434).

Es posible afirmar que para los autores de México: su evolución social la finalidad o el telos de la historia era prever el futuro para impulsar la evolución y el progreso, pero esto último significaba, en el contexto del México de cambio de siglo, conquistar las libertades políticas, que no eran sino la consecuencia

\footnotetext{
${ }^{24}$ Para Sierra se había avanzado con Díaz pero "nos falta devolver la vida a la tierra, la madre de las razas fuertes que han sabido fecundarla, por medio de la irrigación” (Sierra 2005, III: 434).
}

Araucaria. Revista Iberoamericana de Filosofia, Política, Humanidades y Relaciones Internacionales, año $21, \mathrm{n}^{\circ} 42$. Segundo semestre de 2019. Pp. 85-107. ISSN 1575-6823 e-ISSN 2340-2199 doi: 10.12795/araucaria.2019.i42.05 
del desarrollo (progreso) histórico. Cabe apuntar que, en la obra, parece que el progreso, entendido como la obtención de libertades políticas, es fruto de la educación pero también de algo inesperado: la colonización. Esto se debió a que se asumía que la época colonial había cumplido un papel importante porque aportó muchos beneficios; por ejemplo, en "La evolución industrial" Díaz Dufoo se refiere a la organización política "de los tiempos anteriores á la conquista española" (Sierra 2005, III: 107) en términos de "monarquía bárbara, cimentada en un régimen semi-feudal, origen tal vez de arraigados cacicazgos que hondamente han influído en la historia patria" (Ibidem: 108). Esta misma postura la comparte Pablo Macedo, quien en la "Evolución mercantil" habla de las civilizaciones prehispánicas como de "razas primitivas organizadas en diversas tribus, y aunque algunas eran ya sedentarias, apenas si habían comenzado á salir de la edad de la piedra pulida, alcanzando los principios de la del bronce, pero sin llegar á la del hierro" (Sierra 2005, III: 161) ${ }^{25}$.

La tesis de la importancia del proceso colonizador (español) para el progreso de México se sintetizó en Aragón pero sobre todo en Sierra. El primero consideró en su texto que el mestizaje era el elemento que aglutinaba y dirigía la sociedad mexicana en el orden moral, intelectual y material: "La fusión de las civilizaciones española y mexicana fué de tal trascendencia, que señaló desde entonces los destinos de México" (Sierra 2005, I: 26). Sierra fue mucho más tajante, al argüir que "nos falta [...] atraer al inmigrante de sangre europea, que es el único con quien debemos procurar el cruzamiento de nuestros grupos indígenas, si no queremos pasar del medio de civilización, en que nuestra nacionalidad ha crecido, a otro medio inferior, lo que no sería una evolución, sino una regresión" (Sierra 2005, III: 434). La colonización, por tanto, fue entendida como un elemento central, no sólo porque con ella México comenzó su camino hacia el progreso sino, además, porque al hacerlo ingresó en la historia universal, lo que confirmó la tesis de la determinación del avance de la historia hacia el progreso.

\section{Comentarios finales}

En este escrito decidimos aproximarnos a México: su evolución social porque se trata de una obra central en la historiografía positivista mexicana, lo que permite acercarse tanto al positivismo en México como al régimen porfirista que lo cobijó. Como se trata de una obra bastante extensa es imposible abordarla en un sólo escrito, por eso nos enfocamos en algunas de sus partes y

25 Sobre los conquistadores españoles, Pablo Macedo comenta: "[éstos] incurriendo en el gravísimo error, que ya en otras partes de este libro se puntualiza, de no tratar, al someter á los pueblos primitivos, de fomentar en nada y para nada su bien y su prosperidad, sino simplemente de explotar las nuevas conquistas en pro de la metrópoli y de sus hijos" (Sierra 2005, III: 163). 
en dos temas que consideramos relevantes: i) el método empleado en la obra y ii) la concepción de historia predominante en ella. A lo largo de nuestro estudio detectamos que tanto el positivismo comteano como el evolucionismo organicista spenceriano fueron centrales en el libro. El primero porque sienta las bases teóricas generales para la interpretación de los hechos y, el segundo, porque aportó la idea de evolución social, que permitió entender a la nación mexicana como un organismo (social) que evolucionaba (transitaba) a través de etapas históricas perfectamente detectables. En relación a esto, pudimos ver que el eje de la evolución social era la historia, que estudiada, comprendida y desarrollada científicamente, a la manera positivista, servía como elemento que daba sentido y unidad a la sociedad porfirista, al mostrar los cambios por los que la nación había pasado pero, sobre todo, al vislumbrar las etapas por las que el país debía pasar.

Por otro lado, es de reconocer que los autores de México: su evolución social buscaron cumplir con criterios de objetividad y neutralidad valorativa, al entender que éstos le daban mayor validez a sus respectivos textos. Esta actitud, que se suma a la consistencia teórica de la mayoría, impregnada de elementos positivistas y de una acertada incorporación de aspectos liberales, respalda el hecho de que haya sido el trabajo positivista más fecundo del porfiriato. Debemos aclarar, sin embargo, que por diversos motivos no siempre resultó posible cumplir con la mencionada objetividad y neutralidad valorativa. Esto por diversos motivos: 1) porque algunos autores comulgaron con un romanticismo tardío que pretendía retratar a la nación en pleno proceso de integración, de ahí que concibieran conceptos como nacionalidad, carácter nacional o identidad nacional, como si fuesen fuerzas vitales que operaban a la base de los sucesos históricos (Moya López 2003: 33); 2) porque cada uno tuvo intenciones distintas, pues mientras Sierra tenía como propósito describir el desarrollo de las libertades políticas, es decir, hacer una historia en clave política, los demás tenían otros intereses y, por lo mismo, se mostraron más cautos en temas políticos, lo que no significa que hayan defendido -lo que hicieron hasta cierto grado-al régimen porfirista (Matute 2005: 436); 3) porque se permitieron algunas evaluaciones y juicios personales sobre los procesos históricos que analizaban, y al hacerlo introdujeron elementos subjetivos en el estudio de sus temas. De hecho, es interesante resaltar que, salvo Sierra, el resto de los colaboradores mostraron un relativo pesimismo sobre el futuro de la nación, lo que puede resultar paradójico dado su enfoque positivista de progreso y evolución social; sin embargo, esto quizá se explique justo por haber incluido una evaluación del periodo porfirista hasta 1900, ya que al hacerlo los autores se percataron de los retrocesos, en libertades y en temas sociales, causados por el propio régimen. 
Pese a lo anterior, es posible afirmar que todos los autores de la obra participaron de la idea de que el propio devenir histórico mostraba el camino para el progreso (social, político y cultural), y que éste se concretaba a través de la educación y de la enseñanza científica; de ahí que la obra que publicaron resultó fundamental porque coadyuvó a la creación, desde los presupuestos de laicidad, cientificidad y objetividad, de una verdadera historia general de México; lo que abrió las puertas para la edificación de la educación nacional. 


\section{Referencias bibliográficas:}

Alvarado, Lourdes. (1989). “Asociación Metodófila 'Gabino Barreda'. Dos ensayos representativos”. Estudios de Historia Moderna y Contemporánea de México 12: 211-245.

Aragón, Agustín. (2005). "Del territorio de México y sus habitantes”. En México: su evolución social, I, Justo Sierra ed., 7-32. México: J. Ballescá y Compañía, 1900, reimp.

Barreda, Gabino. (2005). “Oración cívica”. En El positivismo en México, editado por Ignacio Sosa. México D.F.: UNAM.

Bartra, Roger. (2014). Anatomía del mexicano. México D.F.: DeBolsillo.

Braudel, Fernand. (1970). La Historia y las Ciencias Sociales. Madrid: Alianza Editorial.

Charles A. Hale. (1989). The Transformation of Liberalism in Late 19th Century Mexico. Princeton: University Press.

Clark de Lara, B. y E. Speckman Guerra, eds. (2005). La república de las letras. Asomos a la cultura escrita del México decimonónico (vol. III, Galería de escritores). México D.F.: IIH-UNAM.

Comte, Auguste. (1830). Cours de philosophie positive. Tomo I. Paris: Rouen fréres Librairies.

Comte, Auguste. (1839). Cours de philosophie positive. Tomo IV. Paris: Bachelier Imprimeur-libraire.

Comte, Auguste. (1842). Cours de philosophie positive. Tomo VI. Paris: Bachelier Imprimeur-libraire.

Comte, Auguste. (1852). Système de politique positive. Tomo II. Paris: Libraires des corps des ponts et chaussées et des mines.

Cosío Villegas, D. (2004). "El Porfiriato: su historiografía o arte histórico", 1949. En Extremos de América. México D.F.: FCE.

Cosío Villegas, D. et al. (1955-72). Historia moderna de México, 10 vols., México D.F.: Hermes.

Covarrubias, José E. y Richard Weiner. (2010). "Political Economy, Alexander Von Humboldt, and Mexico's 1810 and 1910 Revolutions". Rupkatha Journal on Interdisciplinary Studies in Humanities 2 (3): 220-246.

Díaz Dufoo, C. (2005). "La evolución industrial”. En México: su evolución social, III, Justo Sierra ed., 99-158. México: J. Ballescá y Compañía, 1901, reimp.

Flores Hernández, Benjamín. (1983). "Las letras y las armas en México: su evolución social". Estudios de Historia Moderna y Contemporánea de México IX: 35-95.

Florescano, Enrique. (1980). El poder y la lucha por el poder en la historiografía mexicana. México D.F.: Cuadernos de trabajo del Depto. de Investigaciones Históricas-INAH. 
Gonzales, Michael J. (2007). "Imagining Mexico in 1910: Visions of the Patria in the Centennial Celebration in Mexico City". Journal of Latin American Studies 39 (3): 495-533.

Heródoto (2016). Historia. Madrid: Alianza.

Joseph, Gilbert M., y Timothy J. Henderson, eds. (2002). The Mexico Reader, History, Culture, Politics. Durham and London: Duke University Press.

Joseph, Gilbert M., y Jürgen Buchenau. (2013). Mexico's Once and Future Revolution: Social Upheaval and the Challenge of Rule since the Late 19th Century. Durham: Duke University Press.

Kolakowski, Leszek. (1988). La filosofía positiva. Madrid: Cátedra.

Koselleck, Reinhardt. (2001). Los estratos del tiempo: estudios sobre historia. Madrid: Paidós.

Larráinzar, M. (2001). "Algunas ideas sobre la historia y manera de escribir la de México”. En Polémicas y ensayos mexicanos en torno a la historia, editado por J. A. Ortega y Medina. México D.F.: IIH-UNAM.

Lefebvre, G. (1974). El nacimiento de la historiografía moderna. Barcelona: Ediciones Roca.

María y Campos, Alfonso de. (1985). "Porfirianos prominentes: orígenes y años de juventud de ocho integrantes del Grupo de los Científicos, 18461876". Historia Mexicana 34 (4): 610-661.

Macedo, Pablo. (2005). "Evolución mercantil”. En México: su evolución social, III, Justo Sierra ed., 159-247. México: J. Ballescá y Compañía, 1901, reimp.

Matute, Álvaro, y Evelia Trejo. (1991). "La historia antigua en México: su evolución social". Estudios de Historia Moderna y Contemporánea de México 14: 89-106.

Matute, Álvaro. (2005). "Justo Sierra, el positivista romántico”. En La República de las Letras. Asomos a la cultura escrita del México decimonónico, vol. 3, editado por Belem Clark y Elisa Speckman. México D.F: UNAM.

Moya López, L. A. (2003). La nación como organismo. México su evolución social 1900-1902. México D.F.: UAM Azcapotzalco-Miguel Ángel Porrúa.

Moya López, L. A. (1999). "México: su evolución social. 1900-1902. Aspectos teóricos fundamentales". Sociológica 14 (41): 127-156.

Ortega y Medina, J. A. (1980). Teoría y Crítica de la Historia de la Historiografía Cientifico Idealista Alemana. México D.F.: UNAM.

Priego, Natalia. (2012). "Porfirio Díaz, Positivism and 'The Scientists': A Reconsideration of the Myth". Journal of Iberian and Latin American Research 18 (2): 135-150.

Raigosa, Genaro. (2005). "La evolución agrícola". En México: su evolución social, III, ed. Justo Sierra, 5-48. México: J. Ballescá y Compañía, 1901, reimp.

Riguzzi, Paolo. (2009). "From Globalisation to Revolution? The Porfirian Political Economy: An Essay on Issues and Interpretations”. Journal of Latin American Studies 41 (2): 347-368.

Araucaria. Revista Iberoamericana de Filosofia, Política, Humanidades y Relaciones Internacionales, año $21, \mathrm{n}^{\circ} 42$ Segundo semestre de 2019. Pp. 85-107. ISSN 1575-6823 e-ISSN 2340-2199 doi: 10.12795/araucaria.2019.i42.05 
Riva Palacio, V. (1884). México a través de los siglos. Historia general y completa del desenvolvimiento social, político, religioso, militar, artístico, científico y literario de México desde la antigüedad más remota hasta la época actual. Tomo II. México D.F.: Ballescá y Compañía Editores.

Ruiz Gutiérrez, R. (1987). Positivismo y evolución: introducción al darwinismo en México, México D.F.: UNAM.

Saez, Carmen. (1986). “La Libertad' periódico de la dictadura porfirista”. Revista Mexicana de Sociología 48 (1): 217-236.

Sánchez Mármol, M. (2005). "Las letras patrias”. En México: su evolución social, II, Justo Sierra ed., 603-63. México: J. Ballescá y Compañía, 1902, reimp.

Sierra, Justo et. al. México: su evolución social. México: J. Ballescá y Compañía, 1900-02: http://cdigital.dgb.uanl.mx/la/1080119363_C/1080119363_C. html [Consulta: de junio a julio 2017-18].

Sierra, Justo et. al. (2005). México: su evolución social. 3 tomos, 1900-02. Edición facsimilar. México D.F.: Miguel Ángel Porrúa.

Sierra, Justo. (1984a). "Elementos de Historia general", 1888. En Obras Completas, Ensayos y textos elementales de historia, vol. IX. México D.F.: UNAM.

Sierra, Justo. (1984b). "Catecismo de Historia Patria”, 1894. En Obras completas, Ensayos y textos elementales de historia, vol. IX, México D.F: UNAM.

Sosa, Ignacio. (2005). El positivismo en México. México D.F.: UNAM.

Spencer, Herbert. (1966). The Principles of Sociology, 1896. Vols. 6-8 de The Works of Herbert Spencer, 19 vols. Reimp. Osnabrück: Otto Zeller.

Suárez, Luis. (1972). Las grandes interpretaciones de la historia. Bilbao: Ediciones Moretos.

Vázquez, Josefina Z. (1980). Historia de la Historiografia, México D.F.: Ediciones Ateneo.

Zea, Leopoldo. (1968). El positivismo en México. Nacimiento, apogeo y decadencia. México D.F.: FCE.

Zea, Leopoldo. (2001). Conciencia y posibilidad del mexicano. El Occidente y la conciencia de México. Dos ensayos sobre México y lo mexicano. México D.F.: Porrúa. 
